\title{
Cardiac magnetic resonance T2 mapping for monitoring acute cardiac transplant rejection
}

\author{
Asad A Usman ${ }^{1 *}$, Kirsi Taimen ${ }^{1}$, Marie Wasielewski ${ }^{1}$, Saurabh Shah², Jermey D Collins ${ }^{1}$, Jennifer M McDonald ${ }^{1}$, \\ James C Carr $^{1}$ \\ From 2011 SCMR/Euro CMR Joint Scientific Sessions \\ Nice, France. 3-6 February 2011
}

\section{Objective}

To assess the utility of cardiovascular magnetic resonance (CMR) in acute cardiac rejection using T2 mapping.

\section{Introduction}

Cardiac transplantation is the treatment for some patients with end-stage heart failure. After transplantation asymptomatic acute allograft rejection is a major factor impacting survival in the first 12 months. Current transplant monitoring requires frequent right heart catheterizations, endomyocardial biopsies (EMB), and echocardiography. CMR imaging, comparatively less invasive, has been studied previously in the transplanted heart and prolonged T2 relaxation has shown correlation to transplant edema and rejection [1]. We hypothesize that prolonged $\mathrm{T} 2$ relaxation in transplant edema reflects rejection, and that quantitative T2 mapping will correlate with pathological and clinical findings.

\section{Methods}

Patients were recruited from the transplant clinic for CMR within the first year of transplantation or if admitted to hospital for rejection. All MRI scans were performed within 24 hours of EMB. Biopsies were graded according to the International Society for Heart Lung Transplant grading system for cellular rejection with or without immunohistochemistry (IF) marking humoral rejection.

We used a non-contrast multiplanar single-shot and cine TrueFISP imaging sequence. Each patient also

${ }^{1}$ Northwestern University, Chicago, IL, USA

underwent a novel four-chamber and three short axis quantitative T2 mapping sequence using a single-shot T2-prepared SSFP acquisition with three T2-prep echo times: 0, 24, and $55 \mathrm{msec}$. T2 maps were analyzed using the AHA 17 segment model independently by two reviewers (AU and $\mathrm{MW}$ ) blinded to outcomes for interrater and intra-rater reliability.

\section{Results}

A control cohort of 20 cases demonstrated a normal T2 average of $51.2 \pm 2.7 \mathrm{~ms}$. A total of 25 transplant scans were performed with average age $55.8 \pm 13.8$. All patients were on immunosuppressant regimen of prednisone, tacrolimus, with or without mycophenolate mofetil. There were two cellular and one humoral rejections. The average $\mathrm{T} 2$ relaxation time in patients with $0 R / 1 R$ and negative IF was $52.1 \pm 2.4 \mathrm{~ms}$ versus $61.6 \pm$ $3.1 \mathrm{~ms}$ in rejections $(\mathrm{p}<0.05)$. The average ejection fraction for the rejection versus non-rejection cases was not significantly different, $58.7 \pm 12.7 \%$ versus $53.1 \pm 2.2 \%$ ( $>>0.05)$. All rejection cases were rescanned and demonstrated T2 value resolution with treatment. Figure 1

\section{Conclusion}

Preliminary results demonstrate that T2 mapping offers a novel non-invasive tool for transplant monitoring for both cellular and humoral rejection. A larger multi-institution study will help elucidate the sensitivity and specificity of T2 mapping and the possibility of becoming an adjunctive tool in routine transplant monitoring.

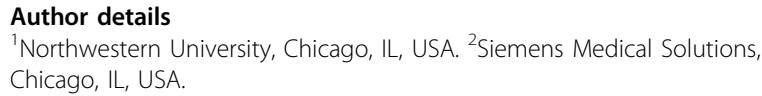

Published: 2 February 2011 


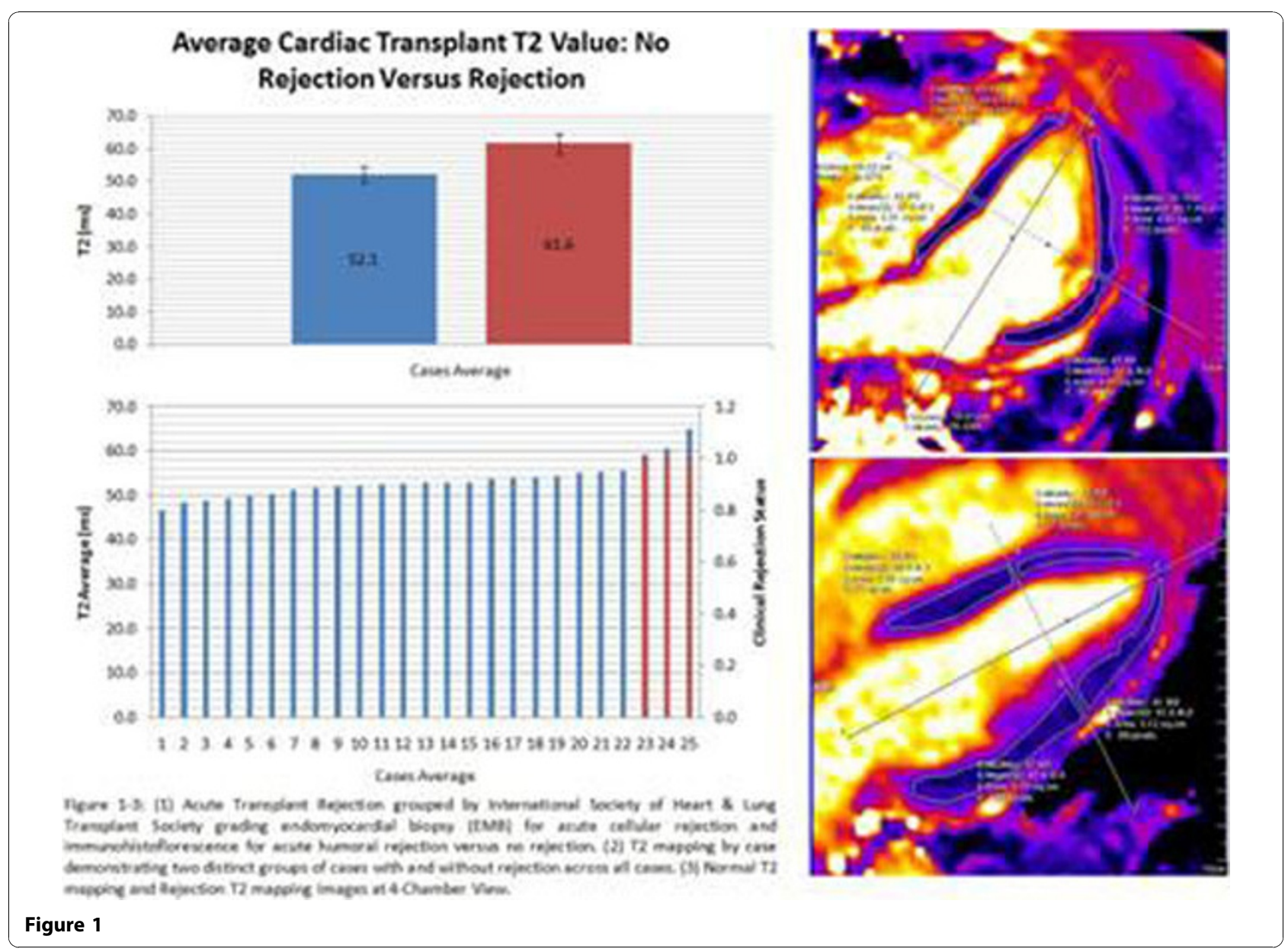

\section{Reference}

1. Marie PY, et al: J.Am.Coll.Cardiology 2001, 37(3):825-831.

doi:10.1186/1532-429X-13-S1-P341

Cite this article as: Usman et al: Cardiac magnetic resonance T2

mapping for monitoring acute cardiac transplant rejection. Journal of

Cardiovascular Magnetic Resonance 2011 13(Suppl 1):P341.

Submit your next manuscript to BioMed Central and take full advantage of:

- Convenient online submission

- Thorough peer review

- No space constraints or color figure charges

- Immediate publication on acceptance

- Inclusion in PubMed, CAS, Scopus and Google Scholar

- Research which is freely available for redistribution 